ORIGINAL ARTICLE

\title{
Physical activity of moderate intensity in leisure time and the risk of all cause mortality
}

\section{J Bucksch}

Br J Sports Med 2005;39:632-638. doi: 10.1136/bjsm.2004.015768

Background: There are conflicting data about the health benefits of moderately intense physical activity. Objectives: To examine the effect of such activity on all cause mortality in a German sample of men and women.

Methods: Physical activity during leisure time of 3742 men and 3445 women aged 30 to 69 was assessed in a baseline questionnaire from 1984 to 1986 . The participants were observed during the follow up period until 1998 when a mortality follow up was conducted.

Results: During the follow up period, 300 women and 643 men had died. The multivariate rate ratios (RR) for the volume of lifestyle activities of moderate intensity (for example, gardening, walking, cycling) compared with sedentary lifestyle showed a clearly protective dose-response relation ( $p$ for trend $<0.001$ )

Correspondence to: Jens Bucksch, Grazer Str 2a/ PO Box 330440 Bremen, Germany; jbucksch@uni-bremen.de

Accepted 6 March 2005 in women but not in men ( $p$ for trend 0.20). Following the recommendation for health enhancing physical activity a second analysis was conducted; 2.5 hours per week taking part in physical activity of moderate intensity decreased the relative risk of overall mortality 10.65 (95\% confidence interval, 0.51 to 0.82$)$ and 0.90 (0.77 to 1.01 ) for women and men, respectively).

Conclusions: The volume of lifestyle activities of moderate intensity in leisure time was inversely associated with all cause mortality in women but not in men. With regard to the health enhancing physical activity recommendation as a threshold, there were favourable findings only in women.

$\mathrm{N}$ umerous epidemiological publications and consensus statements are available about the positive contributions of physical activity towards preventing detrimental health outcomes. ${ }^{12}$ There is a large body of evidence for an inverse association between the total amount or volume of physical activity and all cause mortality for men and women. ${ }^{3-8}$ In Germany, corresponding findings are sparse, but refer to both sexes. ${ }^{910}$ The results of a large number of epidemiological observational studies with prospective design show an inverse dose-response relation between physical activity and all cause mortality. ${ }^{211}$ The shape of this relation seems to be linear. ${ }^{12}$

Despite these facts, the relation between physical activity and health outcomes is not completely understood. Differential effects can be observed if the dimensions of volume (duration, frequency, and intensity), type and context of physical activity (leisure time, work, home, commuting), and sex or age are taken into account. ${ }^{13-15}$ An important issue resulting from the recommendations about the health enhancing effects of physical activity is the emphasis on the need for moderately intense activity to achieve health related benefits. ${ }^{16}$ The rationale for such a recommendation has been documented. ${ }^{17}$ Following the release of the CDC (Centers for Disease Control and Prevention)/ACSM (American College of Sports Medicine) recommendation, there were several investigations of the effects of moderately intense physical activity on all cause mortality. Overall there were mixed findings. In the Caerphilly Study, Harvard Alumni Health Study, and a cohort of British civil servants, only activities of vigorous intensity and not of moderate or light intensity predicted lower rates of premature mortality. ${ }^{8}{ }^{18} 19$ In contrast, several epidemiological studies have observed the benefit of moderately intense physical activity, especially walking, in relation to all cause mortality as well as to the incidence of and mortality from cardiovascular disease. ${ }^{3} 4620-24$
The aim of this study was to analyse the effect of physical activity of moderate intensity on premature death. To address this issue two variables were examined. First, the total duration of moderately intense physical activity ( 3 to $<6$ metabolic equivalents (METs) per week) was determined. Second, the volume of lifestyle activities of moderate intensity was calculated. The variable "lifestyle activities" contained the items walking (including strolling), gardening, and cycling (including commuting to work). This term was coined by Dunn and colleagues ${ }^{25}$ and highlights the difference between the more common daily activities of moderate intensity and structured conditioned physical activities, such as most sports (swimming, jogging, home exercise).

\section{METHODS}

\section{Study subjects and design}

The National Health Survey of the German Federal Institute of Population Research was compiled as an observational study with prospective design (1984 to 1998) and conducted in cooperation with Infratest Health Research. The goals and the methods of this study are described in detail elsewhere. ${ }^{26}$ In brief, the study sample is representative of the general population of former West Germany. The sampling procedure was stratified by age, sex, community size, and federal state. Men and women aged 30 to 69 years with German nationality were contacted by the mailing of a baseline questionnaire in 1984-1986. The self administered questionnaire included a comprehensive spectrum of questions referring to health related behaviour, medical history, and sociodemographic characteristics. The response rate was $69.7 \%$, and 8474 participants were eligible after the baseline

\footnotetext{
Abbreviations: $M$ MET, metabolic equivalent; MLTPA-Q, Minnesota leisure time physical activity questionnaire; MPA, moderate physical activity; RR, rate ratio; VPA, vigorous physical activity
} 
examination. Because of a higher response rate in men than in women at baseline, the number of study subjects was greater for men (4335) than for women (4139). The mortality follow up was carried out in 1998. After exclusion of persons not responding to the questions about physical activity $(\mathrm{n}=67)$ at baseline and persons lost to follow up $(n=1220), 7187$ subjects ( 3742 men and 3445 women) were included in the survival analysis.

Loss to follow up was because of a change of address, technical problems in investigating the address, or for unknown reasons. For the multivariate analysis the sample was reduced furthermore by persons with non-responses for several covariates at baseline. This left 3725 men and 3405 women in the analysis.

During the 16 years of follow up, 643 deaths in men and 300 deaths in women occurred.

\section{Assessment of physical activity}

For the self administered baseline assessment of leisure time physical activity, an adapted short form of the Minnesota leisure time physical activity questionnaire (MLTPA-Q) was used..$^{13}$ The frequency and the duration of 18 activity categories in leisure time were assessed over the previous three months. If a participant took part in an activity at least weekly, the duration summarised per week was reported. Owing to the lack of relative intensity details, for each physical activity the corresponding multiple of resting metabolic rate (MET value) was assigned. ${ }^{27}$ MET values were averaged for those categories of physical activity that have different MET values: walking including shopping, walking to work, and strolling (3.5); hiking/mountain hiking/mountain climbing (7); cycling, including cycling to work or for errands (4); gardening (4); dancing/ballet/jazz dancing (4.8); gymnastics (4); fitness gymnastics/aerobics (6.5); skating/ roller skating (7); swimming (8); jogging/sprinting/running (7); football/basketball/handball/volleyball (6); rowing (6); cross country skiing (7); alpine skiing (6); boxing/wrestling/ fencing/judo/karate (9); table tennis/badminton (5); tennis/ squash (9); home exercise (ergometer, chest expander, rowing machine, weight lifting) (7).

This information was used to construct indices for overall physical activity, lifestyle activities of moderate intensity, and sports activities. The time spent on each physical activity category was multiplied by the corresponding MET value. This represented the volume or total amount of energy expenditure $\left(\mathrm{kcal}_{\mathrm{kg}} \mathrm{kg}^{-1}\right.$.week ${ }^{-1}$ ) resulting from each physical activity category. The overall physical activity index is the sum of energy spent on all 18 activity categories. The lifestyle activities of moderate intensity (lifestyle) index is the sum of energy spent on walking, gardening, and cycling. The sports activity (sport) index is the sum of energy spent on all other physical activity categories (see above). All three indices were divided into four groups. The groups were formed by tertiles of the active participants compared with sedentary individuals.

Additionally, the recommendation for health enhancing physical activity and for improving cardiorespiratory fitness were consulted as a threshold value. ${ }^{16}{ }^{28}$ The time spent in moderately intense physical activity (MPA) ( 3 to $<6$ METs) and in vigorously intense physical activity (VPA) ( $\geqslant 6$ METs) was summarised. Two dichotomous variables for achieving each recommendation were constructed -2.5 hours per week representing 30 minutes of MPA on five days a week, and 1 hour per week corresponding to 20 minutes of VPA on three days a week.

\section{Assessment of covariates}

The self administered baseline questionnaire asked for several confounding variables that could affect the association
Table 1 Characteristics of subjects at baseline (1984 to 1986)

\begin{tabular}{|c|c|c|}
\hline Characteristic & Men $(n=3742)$ & Women $(n=3445)$ \\
\hline \multicolumn{3}{|l|}{ Age groups (years) } \\
\hline $30-43$ & 30.2 & 30.7 \\
\hline $44-54$ & 36.8 & 33.6 \\
\hline $55-69$ & 33.1 & 35.8 \\
\hline \multicolumn{3}{|l|}{ Social class } \\
\hline I (highest) & 19.8 & 12.0 \\
\hline II & 18.2 & 19.9 \\
\hline III & 23.6 & 21.4 \\
\hline IV & 24.4 & 27.7 \\
\hline V (lowest) & 14.0 & 19.1 \\
\hline \multicolumn{3}{|l|}{ Lifestyle index* } \\
\hline 0 & 33.2 & 27.1 \\
\hline $0-<14$ & 22.3 & 22.8 \\
\hline$\geqslant 14-<33.5$ & 22.8 & 25.1 \\
\hline$\geqslant 33.5$ & 21.8 & 24.9 \\
\hline \multicolumn{3}{|c|}{ Recommendation for MPA $\dagger$} \\
\hline No & 41.0 & 36.1 \\
\hline Yes & 59.0 & 63.9 \\
\hline \multicolumn{3}{|c|}{ Recommendation for VPA $\ddagger$} \\
\hline No & 63.2 & 71.2 \\
\hline Yes & 36.8 & 28.8 \\
\hline \multicolumn{3}{|l|}{ Body mass index } \\
\hline$<25 \mathrm{~kg} / \mathrm{m}^{2}$ & 42.4 & 64.2 \\
\hline $25-<30 \mathrm{~kg} / \mathrm{m}^{2}$ & 48.4 & 27.2 \\
\hline$\geqslant 30 \mathrm{~kg} / \mathrm{m}^{2}$ & 9.2 & 8.7 \\
\hline \multicolumn{3}{|c|}{ Chronic disease index $(\%)$} \\
\hline None & 68.7 & 64.6 \\
\hline One & 19.8 & 23.1 \\
\hline At least two & 11.5 & 12.3 \\
\hline \multicolumn{3}{|c|}{ Cardiovascular risk factor index } \\
\hline None & 61.1 & 66.6 \\
\hline One & 22.7 & 21.5 \\
\hline \multirow{2}{*}{\multicolumn{3}{|c|}{$\begin{array}{l}\text { Af lesst two } \\
\text { Alcohol intake }\end{array}$}} \\
\hline & & \\
\hline None/low & 68.5 & 78.6 \\
\hline High & 19.2 & 11.6 \\
\hline Dangerous & 12.3 & 9.9 \\
\hline \multicolumn{3}{|c|}{ Positive dietary habits } \\
\hline $1-5$ & 37.4 & 27.2 \\
\hline 6 and 7 & 45.2 & 44.5 \\
\hline At least 8 & 17.4 & 28.3 \\
\hline \multicolumn{3}{|c|}{ Eats breakfast regularly } \\
\hline Always/often & 90.5 & 92.3 \\
\hline Rare/never & 9.5 & 7.4 \\
\hline \multicolumn{3}{|l|}{ Smoking status } \\
\hline Never & 23.2 & 61.7 \\
\hline Former & 37.1 & 16.7 \\
\hline Current & 39.7 & 21.5 \\
\hline \multicolumn{3}{|c|}{$\begin{array}{l}\text { Values are percentages. } \\
{ }^{*} \text { Calculation of lifestyle index }\left(\mathrm{kcal}^{\mathrm{k}} \mathrm{kg}^{-1} \text {. week }\right. \\
\text { gardening, and cycling per week multiplied by the assigned on walking, } \\
\text { and summarised for each participant } \\
\text { †Recommendation for MPA: at least } 2.5 \text { hours a week of moderately } \\
\text { intense physical activity representing } 30 \text { minutes on five days a week } \\
\text { †Recommendation for VPA: } 1 \text { hour a week of vigorously intense physical } \\
\text { activity corresponding to } 20 \text { minutes on three days a week. } \\
\text { MET, metabolic equivalent; MPA, moderate physical activity; VPA, } \\
\text { vigorous physical activity. }\end{array}$} \\
\hline
\end{tabular}

between physical activity and all cause mortality. These factors are described in more detail elsewhere. ${ }^{10}$ In brief, a five stage social class index was used, comprising the education level, occupational status/employment grade, and household equivalent income. ${ }^{29}$ The body mass index (BMI) was defined as weight $(\mathrm{kg})$ divided by height $(\mathrm{m})^{2}$. An index for self reported cardiovascular disease risk factors was composed. A similar index for chronic diseases was constructed. Information on alcohol intake refers to a current recommendation..$^{30}$ Nutritional information was based on eating breakfast regularly and on an index of positive dietary habits.

\section{Ascertainment of vital status and overall mortality}

Person-years were calculated from the date of baseline survey (1984-1986) to 1998 or to the year of death. Altogether 


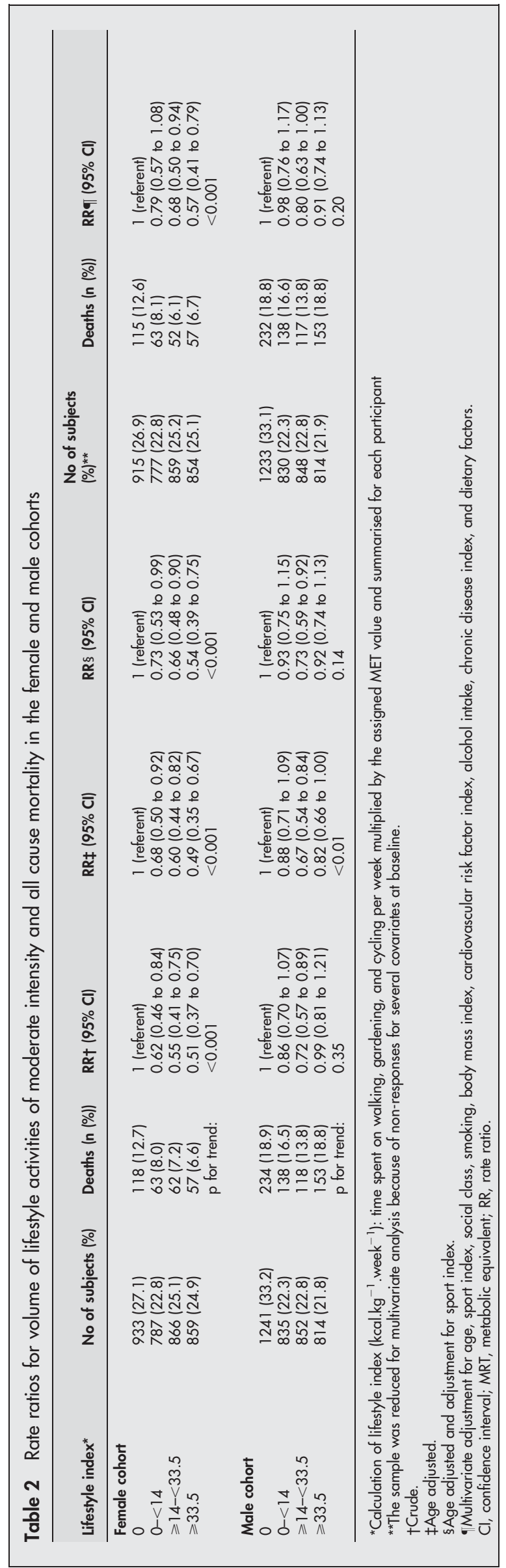

48914 person-years for men and 47200 for women were observed. Deaths were ascertained by the confirmation of the mandatory population registries.

\section{Statistical analyses}

All statistical analyses were undertaken for men and women separately. The baseline characteristics of the study subjects are presented by the frequency distribution across categories of baseline characteristics.

All cause mortality and physical activity were studied by the Cox proportional hazards regression model. ${ }^{31}$ Rate ratios (RRs) are presented with $95 \%$ confidence intervals. The following variables were considered: overall volume of physical activity assessed on all activities, volume of lifestyle activities of moderate intensity (lifestyle index), and the duration of moderately intense physical activity.

The participants were categorised into four groups according to overall volume of physical activity: inactive; up to 19 kcal. $\mathrm{kg}^{-1}$.week ${ }^{-1}$; 19 to $43 \mathrm{kcal} . \mathrm{kg}^{-1}$.week ${ }^{-1}$; and more than $43 \mathrm{kcal} . \mathrm{kg}^{-1}$.week ${ }^{-1}$. Rate ratios were calculated as a function of the four groups. To test for a linear trend, the groups of physical activity were treated as a single ordinal variable.

For lifestyle index four categories were constructed: inactive; 0 to $13 \mathrm{kcal} \cdot \mathrm{kg}^{-1}$. week ${ }^{-1} ; 14$ to $33.4 \mathrm{kcal} \cdot \mathrm{kg}^{-1}$. week $^{-1}$; and $\geqslant 33.5 \mathrm{kcal} . \mathrm{kg}^{-1}$. week ${ }^{-1}$. To ascertain the protective effect of the lifestyle index, two analyses were undertaken. First the sport index was considered simultaneously in the same statistical model. Second, to prevent confounding by the sport index further analyses of the lifestyle index were restricted to the participants (2268 women $(65.8 \%)$ and 2456 men $(65.6 \%)$, respectively) who reported no sports activities. The same cut off points were used. To test for a linear trend across physical activity groups, the groups were treated as a single ordinal variable.

Finally, the duration of MPA was studied. The health enhancing physical activity recommendation was used as a threshold. Two analysis were conducted to ascertain the protective effect of MPA. First, the achievement of the vigorously intense physical activity recommendation was controlled in multivariate analysis. Second, to prevent confounding by the duration of VPA, further analyses of MPA were conducted among the participants who reported no VPA (2335 women (67.8\%) and 2269 men (60.6\%)).

All significance tests were two tailed. The analyses were done using the Statistical Analyses System (SAS, version 6.12.).

The same statistical procedures were applied to analyses that were restricted to people without chronic diseases at entry and which did not include mortality occurring in the first five years of follow up. This calculation was necessary to minimise selection bias because of undetected and undiagnosed diseases. As these analyses did not alter the risk estimates, only the results of the entire cohort over the full time of follow up are described.

\section{RESULTS}

Table 1 provides a description of the study subjects. With respect to physical activity more women than men had a higher lifestyle index. With regard to the sport index, there was no difference between women and men who pursued no sporting activities, but among those who did take part in such activities men had a greater volume (data not shown). The mean for overall volume of physical activity was 33.6 kcal. $\mathrm{kg}^{-1}$. week ${ }^{-1}$ in men and 32.1 in women. A sizable proportion of men and women fulfilled the moderate intensity physical activity recommendation. The results of the vigorous intensity physical activity recommendation were contradictory, and sex differences were observed. More 


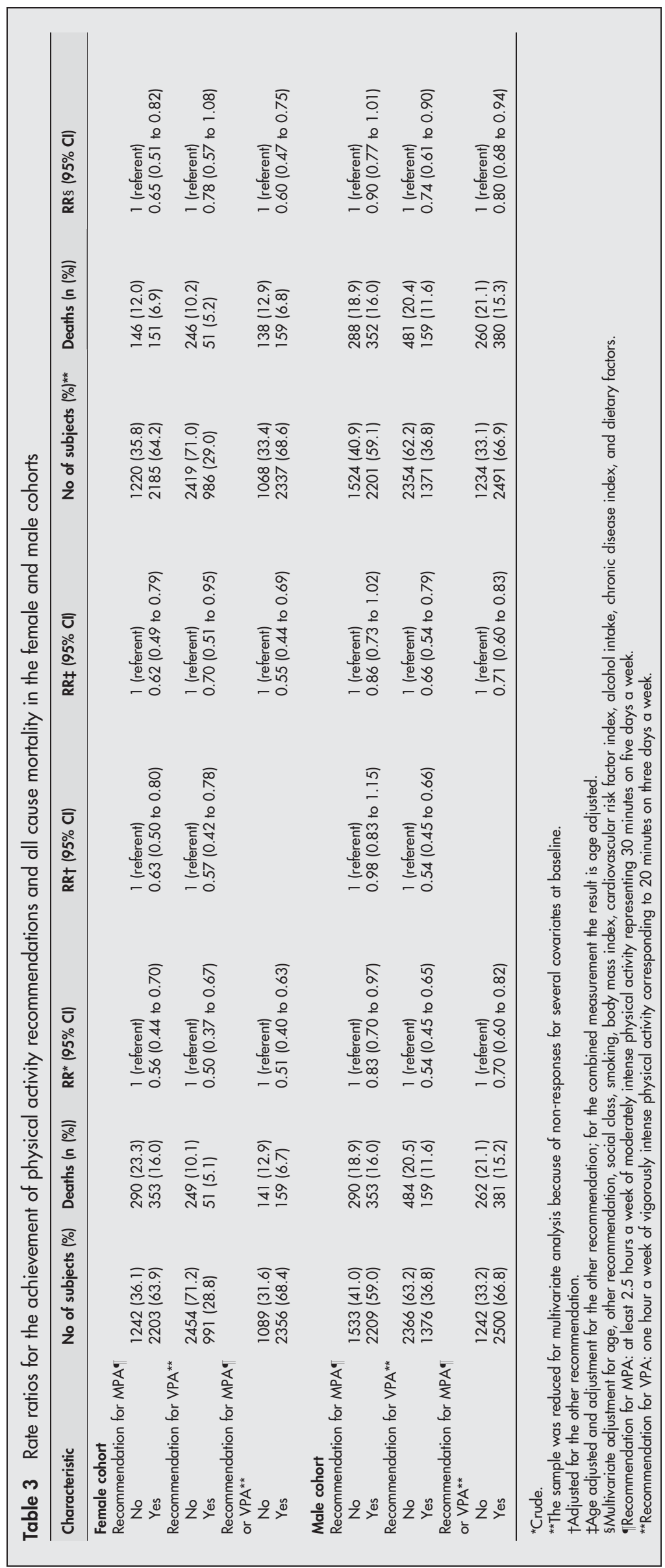


women than men were active in moderately intense physical activity and more men than women did vigorously intense activity.

The loss to follow up was $14 \%$. Larger numbers of younger people were lost to follow up $(\mathrm{p}<0.001)$. This finding mainly reflected the greater mobility of younger people and was not expected to introduce a meaningful bias (data not shown). A more extended comment is provided elsewhere. ${ }^{10}$

The age adjusted RRs for all cause mortality associated with the four groups of overall volume of physical activity were 1 (referent), 0.71 ( 0.58 to 0.88$), 0.74$ ( 0.60 to 0.91 ), and 0.67 (0.54 to 0.82 ) in men ( $\mathrm{p}$ for trend $<0.001$ ), and $\mathrm{l}$ (referent), 0.61 (0.46 to 0.82 ), 0.56 (0.41 to 0.77 ), and 0.39 $(0.28$ to 0.55$)$ in women, ( $p$ for trend $<0.001)$ respectively. In the multivariate model the risk reduction was slightly decreased but the linear relation was also observed in men ( $p$ for trend $<0.05$ ) and in women ( $p$ for trend $<0.001$ ). Excluding deaths in the first five years of follow up affected the relation of overall volume of physical activity to all cause mortality in men. The association was reduced and the linear relation disappeared (data not shown).

Further results of the proportional hazard regression analysis indicated a clear inverse association of lifestyle index with all cause mortality in the female cohort. The effect (table 2) was independent of sports activities. RRs were diluted from the crude, age adjusted, to fully adjusted model, but the finding of the inverse association persisted. The doseresponse relation was observed in all analyses ( $\mathrm{p}$ for trend $<0.01)$. In the multivariate analysis, corresponding RRs for the sport index, with the referent being those not participating in sports activities, were 0.75 (0.5 to 1.13$), 0.9$ (0.58 to $1.40)$, and 0.55 (0.30 to 1.03$)$. In the subgroup of 2268 women $(65.8 \%)$ who did not engage in sporting activities, the multivariate RRs for the lifestyle index were 1 (referent), 0.81 (0.58 to 1.14 ), 0.58 (0.40 to 0.84 ), and 0.49 (0.33 to 0.72 ) ( $\mathrm{p}$ for trend $<0.001$ ).

In men, the association between lifestyle index and mortality was unclear. Only the middle activity level attained a clear effect. No dose-response relation was observed. Adjusting for age, the RRs for middle and high activity level were strengthened. Further adjustment lowered the risk. For the sport index the risk reduction was more distinctive. In the multivariate analysis, corresponding RRs for the sport index, with the referent being those not participating in sporting activities, were 0.94 (0.70 to 1.27$), 0.94$ (0.71 to 1.23$)$, and 0.64 ( 0.46 to 0.88$)$. In the subgroup of 2456 men $(65.6 \%)$ who did not engage in sporting activities, the multivariate RRs for the lifestyle index were 1 (referent), 0.84 (0.66 to 1.10 ), 0.72 (0.55 to 0.96$)$, and $0.90(0.72$ to 1.14$)$ ( $p$ for trend $=0.16$ ).

Persons who achieved recommendation of MPA or VPA, respectively, were at a significantly lower risk of death than their sedentary counterparts. The risk estimates were more pronounced in women (table 3 ). There was a clear risk reduction for the recommendation of MPA. Accomplishing the recommendation of VPA was not related to a further protective influence. In women, 2.5 hours a week of MPA was more predictive than one hour a week of VPA. In the subgroup of 2335 women $(67.8 \%)$ who did not engage in VPA, the multivariate $\mathrm{RR}$ for the moderate intensity recommendation was 0.63 ( 0.49 to 0.82 ).

In men, there was only a small risk reduction for following the recommendation for MPA. VPA seemed to be more predictive. With the adjustment for VPA, the RR of MPA and all cause mortality was diluted to a large extent. In comparison, after adjustment for MPA the RR of VPA was not affected. With regard to the adjustment for age, there was negative confounding in the male cohort. This reflected the finding that men of increasing age were more likely to engage in MPA. In the subgroup of 2269 men $(60.6 \%)$ who did non engage in VPA, the multivariate RR for the moderate intensity recommendation was 0.93 (0.77 to 1.12 ).

\section{DISCUSSION}

The main finding of this study was the reduction in premature deaths resulting from an increase in moderate intensity lifestyle activities (cycling, walking, gardening) during leisure time in women, independent of the other covariates including the volume of sports activities. The risk was also reduced in women who did not take part in any sports activities. In men, the protective influence of lifestyle activities was only small and no linear trend was observed. The volume of sports activities seemed more important. A linear trend of overall volume of physical activity with all cause mortality was observed in both the female and the male cohorts. When the recommendation of health enhancing physical activity ${ }^{16}$ and of improving cardiovascular fitness ${ }^{28}$ were used as a threshold, a similar finding was observed. The results of the female cohort highlighted that 2.5 hours a week of moderately intense physical activity, corresponding 30 minutes on five days a week, were sufficient to lower the risk of all cause mortality.

One German mortality follow up study, which used the same questionnaire in men and women, compared the volume of leisure time physical activity (including all activities) with the volume of a conditioning physical activity, comparable to the sport index. The investigators concluded that the strongest risk reduction occurred in persons with high conditioning activity levels. ${ }^{9}$ The effect of volume of leisure time physical activity was less pronounced but was in a similar direction to that seen for conditioning activity volume.

The finding that women and elderly people attained a larger health benefit from doing physical activity of moderate intensity than middle aged men has been emphasised by other investigators. ${ }^{14}{ }^{15} 32$ The studies showing a more favourable influence of vigorously intense physical activity mostly refer to middle aged men. ${ }^{8}{ }^{18} 19$ In the British Civil Servants Study, physical activity of moderate intensity reduced the risk of mortality only for the men older than 54 years. ${ }^{19}$ Haapanen et al found an inverse relation of all cause mortality with physical activity of both vigorous and moderate intensity in middle aged men. ${ }^{20}$ There were similar findings in the Health Professionals' Follow Up Study ${ }^{24}$ : walking half an hour daily lowered the incidence of cardiovascular disease in men aged 40 to 79 years (relative risk $=0.82(0.67$ to 1.00$))$. Walking pace seemed to be most important, and greater intensities of walking were related to a greater effect on decreasing the risk of cardiovascular disease. ${ }^{24}$ A few studies have shown a protective effect of physical activity of moderate intensity on all cause mortality in middle aged men. ${ }^{3}$ Other studies have confirmed the protective influence of moderately intense physical activity (especially walking) with regard to cardiovascular disease/ coronary heart disease in women. ${ }^{21-23}$ A quantitative review and meta-analysis concluded that one hour of walking a week lowered the risk of cardiovascular disease $(0.80$ (0.74 to $0.87)) .^{33}$

These differences in sex and age may be explained by real differences of activity patterns. Older people and women are more likely to be sedentary and to be less fit than middle aged men. There are consistent data showing that participation in physical activity decreases with age and is greater in men than in women. ${ }^{2}{ }^{34}$ Lee exemplifies the gap between the sexes by the lower energy expenditure level in the Women's Health Study compared with the Harvard Alumni Health Study. ${ }^{15}$ In the present study there was only a small difference between men and women. Population surveys of physical activity in the European Union and Germany 
confirm the age and sex related findings..$^{35-38}$ Findings from the present study and others show that the main differences in sex and age result from alterations in physical activity of vigorous intensity. Physical activity of moderate intensity, such as walking, appears to be more common in women than in men and increases with age..$^{35}$

With an observational study of this type, it is possible that participants self selected for lower physical activity because of certain diseases or undiagnosed chronic disorders. This might result in a biased observation of mortality. ${ }^{2}$ To address such selection bias, the same regression models were used for the entire and healthy cohorts, respectively, and the first five years of follow up were excluded. Similar risk estimates were observed in these additional analyses except for volume of overall physical activity in men. Maybe this reflects the importance of vigorously intense or sporting activities in men. Separate examination of the sport index yielded risk estimates that were not markedly affected by the exclusion of men with chronic diseases at entry or the first years of mortality follow up. ${ }^{10}$

In all, 1220 persons were lost to follow up (14\% of the sample). Thus the results would not be expected to be biased. ${ }^{36}$ Further, larger numbers of younger people were lost in the follow up. This probably reflects the greater mobility of the younger generation. In men particularly, a bias related to health status cannot be excluded because of the significant differences in BMI and cardiovascular disease risk factors. ${ }^{10}$

A few limitations should be highlighted. Physical activity was assessed by self report. It is generally supposed that individuals tend to overestimate physical activity of vigorous intensity and to underestimate the physical activity of moderate and light intensity. ${ }^{39}$ Physical activity was recorded for leisure time, so that unknown non-leisure activities may possibly have influenced the risk estimates.

The questionnaire did not permit examination of the different contexts of physical activity, which is common in physical activity research. The use of the term "lifestyle activities of moderate intensity" was selected to differentiate between common daily activities (such as walking, gardening, and cycling) and conditioning activities (such as sports and exercise). The term refers to behavioural research on physical activity interventions. ${ }^{25}$

The physical activity section was a short adaptation form of the MLTPA-Q. ${ }^{13}$ Examinations suggested moderate external validity (a median correlation coefficient of 0.41 ) for MLTPAQ. ${ }^{13}$ The validity of the questionnaire employed remains unclear. For the reported activities, a test-retest correlation was in the range between 0.5 and $0.8 .^{40}$ The original questionnaire assessed physical activity over the previous year; the adaptation used in the present study assessed activity over the previous three months. This is likely to cause misclassification owing to seasonal variation in physical activity. ${ }^{13}$ Furthermore, there is a potential for misclassification of an individual's physical activity level. This reflects the use of a mean MET value for the activity categories and the lack of assessment of activity change over time, which may lead to non-differential misclassification. Non-differential exposure measurement error is most likely to dilute the association towards unity. ${ }^{11}{ }^{41}$ In this study a large group of men and women fulfilled the CDC/ACSM guidelines. Other prevalence studies using this questionnaire also found a high proportion of people doing lifestyle activities. ${ }^{40}$ Possibly the mean MET value for the walking category did not differentiate adequately between physical activity of light intensity (strolling) and moderate intensity (brisk walking), so that interviewees were misclassified. Precise and accurate measurement methods would strengthen the risk estimates and would offer greater detail about the relation between physical activity and health. ${ }^{21}$ Confounding factors were also self
What is already known on this topic

There is evidence of an inverse relation between all cause mortality and the total amount of physical activity in leisure time, but there are conflicting data about the effect of moderately intense physical activity.

\section{What this study adds}

The risk of all cause mortality was clearly reduced by regular activity of moderate intensity only in women.

reported, which may have led to an unpredictable change in the adjusted RRs. ${ }^{42}$

Absolute intensity values (MET) were assigned for each leisure activity category to calculate the energy expenditure. ${ }^{27}$ This is only a crude measure of intensity and limits the precision of intensity at the individual level. Nevertheless, METs remain a widespread and systematic approach in epidemiological research to apply energy cost estimates of self reported physical activity. To represent the two recommendations of sufficient physical activity, ${ }^{16}{ }^{28}$ an equivalent was applied. The duration and frequency of physical activity were only assessed per week. Therefore in this study 2.5 hours a week of moderately intense and one hour a week of vigorously intense physical activity were used as the reference frames.

Bearing these limitations in mind, the findings of the present study confirm the hypothesis that physical activity of moderate intensity and not less than the recommendation of CDC/ACSM is sufficient to prevent premature death, but this effect was only seen in the female sample. In men, only physical activity of vigorous intensity predicted a clear risk reduction. Two main reasons for the conflicting results are proposed. First, the inconsistency relates to the imprecision in measuring activities of moderate intensity. ${ }^{215} 43$ Second, the differences between studies could be explained by the different characteristics of the study participants such as sex, age, and fitness level. ${ }^{14}{ }^{15}$ Possibly middle aged men have, on average, a generally greater level of physical activity or are more fit than women or older people, and therefore need more physical activity of vigorous intensity for health benefits. ${ }^{1544}$ The CDC/ACSM recommendations for health enhancing physical activity seem suitable as a general guideline intended for sedentary people. More specific guidelines might emphasise the differences of characteristics such as age, sex, and physical fitness for preventive effects. $^{14} 15$

\section{ACKNOWLEDGEMENTS}

I thank the German Federal Institute of Population Research (Wiesbaden) for providing the data of the "Lebenserwartungssurvey" for this investigation. I am grateful to Uwe Helmert, Petra Kolip, and Elisabeth Schröder for their help.

Competing interests: none declared

\section{REFERENCES}

1 US Department of Health and Human Services. Physical activity and health. A report of the Surgeon General. Atlanta, GA: US Department of Health and Human Services, Centers for Disease Control and Prevention, National Center for Chronic Disease Prevention and Health Promotion, 1996.

2 Dishman RK, Washburn RA, Heath GW. Physical activity epidemiology. Champaign: Human Kinetics, 2004.

3 Leon AS, Myers MJ, Connett J. Leisure time physical activity and the 16-year risks of mortality from coronary heart disease and all-causes in the Multiple Risk Factor Intervention Trial (MRFIT). Int J Sports Med 1997;18:208-15. 
4 Villeneuve PJ, Morrison HI, Craig CL, et al. Physical activity, physical fitness, and risk of dying. Epidemiology 1998;9:626-31

5 Weller I, Corey P. The impact of excluding non-leisure energy expenditure on the relation between physical activity and mortality in women. Epidemiology 1998:9:632-5.

6 Andersen BL, Schnohr P, Schroll M, et al. All-cause mortality associated with physical activity during leisure time, work, sports, and cycling to work. Arch Intern Med 2000;160:1621-8.

7 Oguma Y, Sesso HD, Paffenbarger RS, et al. Physical activity and all cause mortality in women: a review of the evidence. Br J Sports Med 2002;36: 162-72.

8 Yu S, Yarnell JWG, Sweetnam PM, et al. What level of physical activity protects against premature cardiovascular death? The Caerphilly study. Heart 2003;89:502-6

9 Mensink GBM, Deketh M, Mul MDM, et al. Physical activity and its association with cardiovascular risk factors and mortality. Epidemiol 1996;7:391-7.

10 Bucksch J, Helmert U. Leisure time sports activity and all-cause-mortality in West-Germany (1984-1998). Z Gesundheitswiss 2004;12:351-8.

11 Jakes RW, Wareham NJ. Epidemiology of activity and physical health. In: McKenna J, Riddoch C, eds. Perspectives on health and exercise. Basingstoke: Palgrave Macmillan, 2003:33-60.

12 Lee IM, Skerrett PJ. Physical activity and all-cause mortality: What is the doseresponse relation? Med Sci Sports Exerc 2001;33(suppl):S459-71.

13 Montoye HJ, Kemper HCG, Saris WHM, et al. Measuring physical activity and energy expenditure. Champaign: Human Kinetics, 1996.

14 Shephard RJ. What is the optimal type of physical activity to enhance health? BrJ Sports Med 1997;31:277-84.

15 Lee IM. No pain, no gain? Thoughts on the Caerphilly study. Br J Sports Med 2004;38:4-5.

16 Pate RR, Pratt M, Blair SN, et al. Physical activity and public health: a recommendation from the Centers for Disease Control and Prevention and the American College of Sports Medicine. JAMA 1995;276:402-7.

17 Blair SN, LaMonte MJ, Nichaman MZ. The evolution of physical activity recommendations: how much is enough? Am J Clin Nutr 2004;79(suppl):913-20

18 Lee IM, Paffenbarger RS. Associations of light, moderate, and vigorous intensity physical activity with longevity: The Harvard Alumni Health Study. Am J Epidemiol 2000;151:293-9.

19 Morris JN, Clayton DG, Everitt MG, et al. Exercise in leisure time: coronary attack and death rates. Br Heart J 1990;63:325-34.

20 Haapanen N, Miilunpalo S, Vuori I, et al. Characteristics of leisure time physical activity associated with decreased risk of premature all-cause and cardiovascular disease mortality in middle-aged men. Am J Epidemiol $1996 ; 143: 870-80$

21 Manson JE, Hu FB, Rich-Edwards JW, et al. A prospective study of walking as compared with vigorous exercise in the prevention of coronary heart disease in women. N Engl J Med 1999:341:650-8.

22 Lee IM, Rexrode KM, Cook NR, et al. Physical activity and coronary heart disease in women. Is "No pain, no gain" passé? JAMA 2001;285:1447-54.

23 Manson JE, Hu FB, Rich-Edwards JW, et al. Walking compared with vigorous exercise for the prevention of cardiovascular events in women. N Engl J Med 2002;341:716-25.
24 Tanasescu M, Leitzmann MF, Rimm EB, et al. Exercise type and intensity in relation to coronary heart disease in men. JAMA 2002;288:1994-2000.

25 Dunn AL, Andersen RE, Jakicic JM. Lifestyle physical activity interventions. History, short- and long-term effects, and recommendations. Am J Prev Med 1998;15:398-412.

26 Gärtner K. Lebensstile und ihr Einfluss auf Gesundheit und Lebenserwartung Der Lebensrwartungssurvey des BiB. Projekt und Materialdokumentation. Wiesbaden: BIB, 2001.

27 Ainsworth BE, Haskell WL, Whitt MC, et al. Compendium of physical activities: An update of activity codes and MET intensities. Med Sci Sports Exerc 2000;32(suppl):S498-516

28 ACSM Position Stand. The recommended quantity and quality of exercise for developing and maintaining cardiorespiratory and muscular fitness in healthy adults. Med Sci Sports Exerc 1990;22:265-74.

29 Helmert U. Soziale Ungleichheit und Krankheitsrisiken. Augsburg: Maro, 2003.

30 British Medical Association. Alcohol: guidelines on sensible drinking. London: BMA Publishing Group, 1995

31 Allison PD. Survival analysis using the SAS system. A practical guide. Cary; North Carolina: SAS Institute Inc, 1995.

32 Lee IM. Physical activity in women. How much is good enough? JAMA 2003;290:1377-9.

33 Oguma Y, Shinoda-Tagawa T. Physical activity decreases cardiovascular disease risk in women. Review and meta-analysis. Am J Prev Med 2004; 26:407-18.

34 Trost SG, Owen N, Bauman AE, et al. Correlates of adults' participation in physical activity: review and update. Med Sci Sports Exerc 2002;34:1996-2001.

35 Rütten A, Abu-Omar K. Prevalence of physical activity in the European Union. Soz Praventiv Med 2004:49:281-9.

36 Kristman V, Manno M, Cote P. Loss to follow-up in cohort studies: how much is too much? Eur J Epidemiol 2004; 19:751-60.

37 Mensink GBM. Korperliche Aktivitat. Gesundheitswesen 1999;61(suppl):S126-31.

38 Varo JL, Martinez-Gonzales MA, Irala-Estevez J de, et al. Distribution and determinants of sedentary lifestyles in the European Union. Int J Epidemiol 2003;32:138-46.

39 Sallis JF, Saelens BE. Assessment of physical activity by self-report: status, limitations, and future directions. Res Q Exerc Sport 2000;71:1-14.

40 Mensink GBM. Movement and circulation. Population studies on physical activity and cardiovascular disease risk. Ponsen \& Looijen, 1997.

41 Andersen LB. Relative risk of mortality in the physically inactive is underestimated because of real changes in exposure level during follow-up. Am J Epidemiol 2004;160:189-95.

42 Szyklo M, Nieto FJ. Epidemiology. Beyond the basics. Gaithersburg: Aspen Publication, 2003.

43 Lee IM, Paffenbarger RS. How much physical activity is optimal for health? Methodological considerations. Res Q Exerc Sport 1996;67:206-8.

44 Bassuk SS, Manson JE. Physical activity and cardiovascular disease prevention in women: how much is good enough? Exerc Sport Sci Rev 2003;31:176-81

\section{ELECTRONIC PAGES}

\section{Online case reports}

$\mathrm{T}$ he following electronic only articles are published in conjunction with this issue of BJSM

\section{Results of compartment decompression in chronic forearm compartment syndrome: six case presentations}

$\mathrm{H}$ Zandi, S Bell

Background: There are few reports concerning chronic compartment syndrome producing symptoms in the forearm, although in the lower limb this is a well recognised condition.

The objective was to demonstrate that chronic compartment syndrome is a cause of exercise induced forearm pain and transient upper limb dysfunction and that forearm compartment decompression can reliably relieve the associated symptoms.

Methods: Six patients with a flexor compartment chronic compartment syndrome, documented by pressure studies, had forearm compartment decompression.

Results: All patients had good relief of their exercise associated forearm pain following the decompression.
Widening of the incisional scar was frequently reported.

Conclusion: Forearm compartment decompression is effective in relieving the symptoms related to chronic forearm compartment syndrome.

(Br J Sports Med 2005;39:e35) http://bjsm.bmjjournals.com/ cgi/content/full/39/9/e35

\section{Pseudo compartment syndrome of the calf in an athlete secondary to cystic adventitial disease of the popliteal artery}

$\mathrm{N} \mathrm{Ni}$ Mhuircheartaigh, E Kavanagh, M O'Donohoe, et al We report a patient with calf pain induced by sport and exercise, initially thought to represent compartment syndrome, in whom MRI and duplex ultrasound ultimately revealed cystic adventitial disease of the popliteal artery.

Surgical de-roofing of the popliteal artery resulted in complete resolution of symptoms with return to sporting activities.

(Br J Sports Med 2005;39:e36) http://bjsm.bmjjournals.com/ cgi/content/full/39/9/e36 